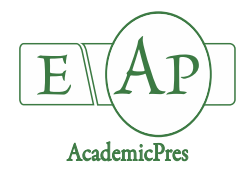

Ahmad R et al. (2020)
Notulae Botanicae Horti Agrobotanici Cluj-Napoca 48(3):1141-1154
DOI: $10.15835 /$ nbha48311957
Research Article

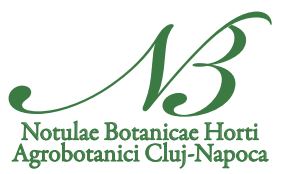

\title{
Variation in Nigella sativa quality and its standardization via instrumental analysis: A study based on geographical origin
}

\author{
Rizwan AHMAD ${ }^{1 *}$, Niyaz AHMAD ${ }^{1}$, Mohd AMIR ${ }^{1}$, \\ Fatima AlJHISI ${ }^{1}$, Marwah H. ALAMER ${ }^{1}$, Heba R. AL-SHABAN ${ }^{1}$, \\ Bayan M. ALSULTAN ${ }^{1}$, Zainab A. ALSADAH ${ }^{1}$, \\ Noor A. ALDAWOOD ${ }^{1}$, Shahanas CHATHOTH ${ }^{2}$, Aslam KHAN ${ }^{3}$ \\ ${ }^{I}$ Imam Abdulrahman Bin Faisal University, Natural Products and Alternative Medicines, Department of Pharmaceutics and \\ Pharmaceutical Chemistry, College of Clinical Pharmacy, P.O Box \# 1982, Dammam 31441, Kingdom of Saudi Arabia; \\ rizvistar_36@yahoo.com; rareiyadh@iau.edu.sa("corresponding author);niyazpharma@gmail.com; matahmad@iau.edu.sa; \\ fsaljishi@iau.edu.sa; Marwh.alamer1998@gmail.com; Hebarm1998@gmail.com;Bayan.215b@gmail.com; \\ Zainabalawi77@gmail.com;noor82471@gmail.com \\ ${ }^{2}$ Imam Abdulrahman Bin Faisal University, Department of Biochemistry, College of Medicine, Dammam, \\ Kingdom of Saudi Arabia; schathoth@iau.edu.sa \\ ${ }^{3}$ King Saud bin Abdulaziz University for Health Sciences, Basic Sciences Department, College of Science and Health Professions, \\ Ministry of National Guard Health Affairs, Jeddah, Kingdom of Saudi Arabia; Khanasl@ksau-hs.edu.sa
}

\begin{abstract}
Black seeds (Nigella sativa) owe an important place due to its more demand as a food as well as medicine. A lack of information does exist regarding the quality and safety for market-available food-grade samples of black seed (BS). The aim of this study is to investigate the quality and standardize the BS samples according to world health organization (WHO) guidelines of instrumental analysis and pharmacological activities. Instrumental analysis was performed with the help of ASE (accelerated solvent extraction), IR (infrared spectroscopy), UHPLC (ultra-high-performance liquid chromatography) and NMR (nuclear magnetic resonance spectroscopy) whereas ash values and chemical tests were applied for physicochemical analysis. DPPH (2,2-diphenyl-1-picrylhydrazyl), ABTS (2,2'-azino-bis (3-ethylbenzothiazoline-6-sulfonic acid) and cytotoxicity assay were performed as well. A high extract yield $(\mathrm{g})$ with recovery of $4.4 \pm 7.7(22 \%)$ for Pakistani, $3.3 \pm 4.7(16.5 \%)$ for Indian and $3.02 \pm 10.2(15.1 \%)$ for Saudi Arabian sample. Chemical tests showed the presence of phenolic compounds and flavonoids. Saudi Arabian samples showed less amount for ash values (total-, water soluble- and acid insoluble ash). The samples were standardized further with the help of NMR and IR. A significant amount of micro- and macronutrients was observed in Saudi Arabian sample. With regard to the major active substance Thymoquinone (THQ; ng/mL), the order of concentration was observed as; Saudi Arabian sample (33141.1) > Pakistani (7677.2) > Indian sample (3998.6). A more potency for Saudi Arabian sample was observed during antioxidant and cytotoxicity assays. The method was successful to effectively discriminate the samples from different geographical origin, in terms of quality.
\end{abstract}

Keywords: India; instrumental analysis; Nigella sativa; Saudi Arabia; standardization; quality 


\section{Introduction}

Nigella sativa (N. sativa), family; Ranunculaceae, or black seed (BS), is a globally used medicinal plant which is an intact part of various systems including "The medicine of Prophet Mohammad P.B.U.H", "Indian traditional medicine" and "Unani Tibb". It grows in the Middle East, Eastern Europe, and Western Asia where they are used in food as a flavoring additive in breads and pickles (Tavakkoli et al., 2017; Srinivasan, 2018). The widely applied therapeutic potential for BS consist of its antioxidant, anticancer, antihyperlipidemic, antidiabetic, immunomodulator, antitussive, analgesic, antimicrobial, anti-inflammatory, spasmolytic, and bronchodilator activities. Pre-clinical and clinical trials have investigated its efficacy using the seed essential oil and its bioactive substance Thymoquinone (THQ) (Srinivasan, 2018) and a number of marketed products are available for BS; “ The Blessed Seed”, “Z-Company”, "Hab-e-Shifa”, “Amazing Nutrition”, “Organika Health Products Inc." and "Complete Organics" available at i-Herb.com and Amazon.com (https://www.amazon.com; https://www.iherb.com). The extraction techniques for BS ranges from conventional to ultrasound-assisted extraction and organic solvent extraction of maceration and Soxhlet techniques however, these methods take lengthy time for extraction with large volumes of solvents, large amount of matrix and labor-intensive procedures. The desire to reduce such disadvantages has led to the development of newer techniques for extraction of analyte including; pressurized liquid extraction (PLE), microwave assisted extraction (MAE), supercritical fluid extraction (SFE) and accelerated solvent extraction (ASE). MAE is a technology based on combination of microwave and conventional solvent extraction which is used for the extraction of nutraceuticals with less time, less solvent and providing more extraction yield. The moistened volume is an important factor for MAE and $N$. sativa contains very less moisture levels (Liu et al., 2012). In SFE technique; the extraction was performed at $40{ }^{\circ} \mathrm{C}$, pressure at 600 bars and the flow rate was maintained at $30 \mathrm{~mL} / \mathrm{min}$ whereas, the entire extraction process required $3 \mathrm{~h}$ (Linjawi et al., 2015). ASE, utilizes minute amount for sample, solvent and time used during extraction process (Liu et al., 2012). Current study utilized ASE, which is considered a rapid and effective extraction method for natural products. With respect to quantitative determination of THQ, various analytical instruments have been applied such as; reverse-phase high-performance liquid chromatography (flow rate (FR), $2 \mathrm{~mL} / \mathrm{min}$ and retention time (RT), $6 \mathrm{~min}$ ) (Iqbal et al., 2018), high pressure liquid chromatography (FR, $1.0 \mathrm{~mL} / \mathrm{min}$ and $\mathrm{RT}, 8.7 \mathrm{~min}$ ) (Dinagaran et al., 2016), gas chromatography (Ahmad et al., 2018) and electrospray ionization mass spectrometry (Agbaria et al., 2015). Herein, a previously developed and validated method of UHPLC is applied (Ahmad et al., 2020) to assist the extracted sample for THQ quantification. UHPLC is effective compared to other methods, as it utilizes smaller column with less particles size which increases the number of efficiency plates for less retention time and flow rate (Aboul-Enein and Abou-Basha, 1995; Ahmad et al., 2018). Furthermore, the quality for black seed samples will be evaluated and standardized as per WHO (World health organization, 2011) procedures including; instrumental analysis (IR, ASE, UHPLC, NMR) for extraction and quantitation, biological evaluation (in vitro or in vivo pharmacological activities). In this study, DPPH assay along with anticancer activity will be performed for black seed sample. The black seeds samples from three different geographical origins of Saudi Arabia, Pakistan, and India are studied for quality variation and at the same time standardized with regard to Thymoquinone (THQ). Biological activities will be tested for further confirmation of the quality.

\section{Materials and Methods}

\section{Chemical and solvent used}

Sigma Aldrich (St. Louis, MO, U.S.A) chemicals; Thymoquinone (2-Isopropyl-5-methyl-1,4benzoquinone; $\geq 98 \%$ ), DPPH (2,2 diphenyl 1 picrylhydrazide), ABTS (2,21-azino-bis (3ethylbenzothiazoline-6-sulphonic acid), Potassium persulfate $\left(\mathrm{K}_{2} \mathrm{~S}_{2} \mathrm{O}_{8}\right)$. Merck (Darmstadt, Germany) 
products; $\mathrm{MeOH}, \mathrm{n}-\mathrm{Hex}, \mathrm{AA}$ (HPLC-/analytical grade). Bedfrod, MA, USA system was used for purification of water. Thermo-Fisher chemical and solvents; MCF7 (Breast cancer cell line of ATCC, Rockville, MD, USA), DMEM (Dulbecco's modified Eagle's medium with FBS 10\%, penicillin and streptomycin 1\%).

\section{Instruments used}

FT-IR, Fourier transform-infrared spectroscopy: NICOLET iS50 (Thermo Fisher Scientific, 5225 Verona Road, Madison, WI 53711, USA); Thermo Scientific ${ }^{\mathrm{m}}$ Reacti-Therm ${ }^{\mathrm{m}}$ Heating and Stirring Modules (Reacti-therm III \# TS-18824 Heating module \& Reacti-Vap III\# TS-18826 evaporation unit) and Soxhlet apparatus (BUCHI Rotary evaporator ${ }^{\circ}$, Switzerland) were used. Incubator; Binder, Bohemia, New York, USA (containing humidified atmosphere of $95 \%$ air and $5 \% \mathrm{CO}_{2}$ at $37^{\circ} \mathrm{C}$ ).

\section{Samples used}

Three different geographical sample used in the study were collected from India, Saudi Arabia and Pakistan. The samples remained the same as studied previously by Ahmad et al., 2020 which were identified by Dr. Amir (Department of Natural products and Alternative medicines, Imam Abdulrahman Bin Faisal University, Saudi Arabia).

\section{Extraction of black seed samples}

For extraction of BS, an in-house ASE (accelerated solvent extraction) method was developed and validated previously (Ahmad et al., 2020). Three stainless steel cells (ASE-SST) were loaded individually with sample ( $20 \mathrm{~g})$, selected for study (Saudi Arabia, Pakistan, India). The conditions used were; $66 \mathrm{~mL}$ capacity cells using n-Hex as a solvent at $70^{\circ} \mathrm{C}$ and pressure (100atm).

\section{Identification and quantification via UHPLC-DAD}

The previously ASE extracted samples for the three geographical samples were quantified for THQ amount, as per the method reported in our previous study (Ahmad et al., 2020). The required stock and standard solutions as well as CC (calibration curve) were prepared. The chromatography conditions are mentioned in detail in previous report where an isocratic elution of 50:50\% (ACN:AA), FR (flow rate) of 0.2 $\mathrm{mL} / \mathrm{min}$ and IV (injection volume) of $10 \mu \mathrm{L}$ was applied. (Ahmad et al., 2020)

\section{Infra-red spectroscopy (IR) profiling}

The three different geographical samples were studied for IR profiling of THQ. To prepare sample; extract $(0.1 \mathrm{mg})$ was blended with potassium bromide $(100 \mathrm{mg})$ and pellet was prepared via pressing. The spectrum was recorded via FT-IR ( 400 to $4000 \mathrm{~cm}^{-1}$ ). (Ahmad et al., 2018)

\section{HNMR (nuclear magnetic resonance spectroscopy) profiling}

\section{Sample preparation}

Individual sample $(10 \mathrm{mg})$ was vortexed with $1 \mathrm{~mL}$ of DMSO-d6 solvent for $30 \mathrm{~s}$, followed by sonication $(20 \mathrm{~min}$ ) and centrifugation $(14,000 \mathrm{rpm} ; 5 \mathrm{~min})$. A $600 \mu \mathrm{L}$ supernatant was collected in $5 \mathrm{~mm}$ NMR-glasstube and analyzed.

\section{NMR spectroscopic analysis}

The software used was TopSpin $(3.2 \mathrm{pl} 7)$ and operating set of conditions; ${ }^{1} \mathrm{H}(300 \mathrm{MHz})$ and ${ }^{13} \mathrm{C}(75$ $\mathrm{MHz}$ ), pulse width (proton 12.25 and carbon $90^{\circ}$ with $10.5 \mu \mathrm{s}$ ), scans for ${ }^{1} \mathrm{H}(16)$ and ${ }^{13} \mathrm{C}(256)$, recycle time (2-3 s). IS (internal standard) used was tetra methyl silane (TMS) in the scan region for ${ }^{1} \mathrm{H}(0-10 \mathrm{ppm})$ and ${ }^{13} \mathrm{C}$ NMR (0-200 ppm). 


\section{$\underline{\text { Chemical tests }}$}

Chemical tests as part of the physicochemical evaluation were carried out for all the samples in order to explore the presence of phytochemical class present. The tests followed the procedure reported previously, in order to find the presence of chemical groups; alkaloids, steroids, flavonoids, saponins and phenolic compounds (Khandelwal, 2007; WHO, 2011).

Ash values

The samples were studied for ash values in terms of total-, water soluble- and acid insoluble ash, as per WHO requirements (Khandelwal, 2007; WHO, 2011).

Antioxidant (in vitro) activities

2,2 diphenyl 1 picrylhydrazide (DPPH) activity

The samples and its dilution were evaluated for free radical scavenging activity, according to the method reported (Ahmad et al., 2016). The individual $\mathrm{IC}_{50}$ values were calculated using the formula mentioned below.

$\%$ DPPH radical scavenging activity $=(\mathrm{ODC}-\mathrm{ODS}) / \mathrm{ODC} \times 100$

ODC and ODS= absorbance for control and test samples, respectively.

2,2'-Azino-Bis-3-Ethylbenzothiazoline-6-Sulfonic Acid (ABTS ${ }^{+}$) assay

All the samples were tested for its potential to entrap $\mathrm{ABTS}^{+}$free radical. The total antioxidant activity was evaluated using the previous report. (Ahmad et al., 2016) Triplicate readings were noted and \%decrease was observed.

3-(4,5-Dimethylthiazol-2-yl)-2,5-diphenyltetrazolium bromide (MTT assay for cytotoxicity)

Cell culture and cell viability tests (conditions and drug treatment)

The growth of MCF7 in DMEM was performed in an incubator and the extract in different dilution was applied in cell grown ( $80 \%$ confluence). The MTT procedures along with viability for cells in these medias, following extract application in various dilutions, is mentioned in detail in the report available. (Ahmad et al., 2020b)

\section{Statistical analysis of samples}

K-mean cluster distribution produced two clusters; 1 (1) and 2 (2). Cluster 1 consisted of Saudi Arabian sample only and the major features for cluster 1 are (Figure 4); high UHPLC-DAD result (THQ amount) with low extract yield, ash values (total, acid insoluble and water-soluble ash) and low $\mathrm{IC}_{50}$ value for DPPH, ABTS and cytotoxicity. Cluster 2 consisted of 2 samples (Pakistani and Indian black seed) with major features; high extract yield with low UHPLC-DAD amount (THQ) and high ash values (total, acid insoluble, water soluble ash), high $\mathrm{IC}_{50}$ value for DPPH, ABTS and low percentage for cytotoxicity.

Principle component analysis (PCA) proposed two components with an individual contribution (variance) of 66.73 (PC1) and 33.261 (PC2) and combined variance of 100\% (Table 7). UHPLC and extract value were not loaded in PC1 (Figure 5) which shows a high extract yield for Pakistani sample hence, theoretically more active substance may be present in this extract however, it is not true. UHPLC quantification confirmed that despite high extract yield, more THQ was present in Saudi Arabian sample. Similarly, Ash values, antioxidant and cytotoxicity assays were observed comparatively better in Saudi Arabian sample and were loaded in PC1 with major variance of $66.73 \%$. Among the tested parameters $67 \%$ of the properties were found more better in Saudi Arabian sample as compared to Pakistani and Indian sample. 


\section{Results}

Yield with recovery (\%)

More yield (g) and recovery of $4.4 \pm 7.7$ (22\%) was observed for Pakistani black seed sample, followed by Indian $3.3 \pm 4.7$ (16.5\%) and Saudi Arabian 3.02 \pm 10.2 (15.1\%) samples as shown in Table 1.

The solvent used was $47-52 \mathrm{~mL}(49.5 \pm 2 \mathrm{~mL})$ with a time duration of $40-44 \mathrm{~min}(42 \pm 2 \mathrm{~min})$.

\section{Chromatographic analysis}

The accuracy of the method was $97.3 \pm 3.6$ using linearity concentrations $(300-5000 \mathrm{ng} / \mathrm{mL})$. The regression line showed $r^{2}$ value of 0.97 . The quantification showed more THQ $(\mathrm{ng} / \mathrm{mL})$ for Saudi Arabian sample (33141.1) followed by Pakistani (7677.2) and Indian (3998.6) sample (Table 2).

Table 1. Extraction yield and recovery (\%) for black seeds commercial samples

\begin{tabular}{|c|c|c|c|c|}
\hline \multirow{2}{*}{ Temperature } & \multirow{2}{*}{ Solvent } & Sample & $\begin{array}{c}\text { Extract yield } \\
(\mathrm{g})\end{array}$ & $\begin{array}{c}\text { Recovery }(\%) \& \\
\text { SD }( \pm)\end{array}$ \\
\hline \multirow{3}{*}{$70{ }^{\circ} \mathrm{C}$} & \multirow{3}{*}{$\mathrm{n}$-Hexane } & Saudi Arabia & 3.02 & $15.1 \pm 10.2$ \\
\cline { 3 - 5 } & & Pakistan & 4.4 & $22 \pm 7.7$ \\
\cline { 2 - 5 } & \multicolumn{2}{|c|}{ India } & 3.3 & $16.5 \pm 4.7$ \\
\hline \multicolumn{2}{|c|}{ Total recovery } & 10.7 & \\
\hline \multicolumn{2}{|c|}{ Recovery $(\%)$} & 17.8 & \\
\hline
\end{tabular}

Table 2. UHPLC quantification of THQ in commercial black seed samples

\begin{tabular}{|c|c|}
\hline \multicolumn{2}{|c|}{ Quantification for THQ $(\mathrm{ng} / \mathrm{mL})$} \\
\hline Sample & Amount \\
\hline Saudi Arabia & 33141.1 \\
\hline Pakistan & 7677.2 \\
\hline India & 3998.6 \\
\hline
\end{tabular}

Accuracy $=97.3 \pm 3.6$; linearity range $=300-5000 \mathrm{ng} / \mathrm{mL} ; \mathrm{r}^{2}=0.97$

\section{Infra-red analysis}

The spectrum for IR (Figure 1) and Table 3, reveals peaks in the region of 4000-400 $\mathrm{cm}^{-1}$ which are characteristics of THQ. The presence of commonly present triglyceride molecule along with the fatty acids in the region confirms the presence of THQ in all extracts.

Table 3. IR peaks observed for black seed samples

\begin{tabular}{|c|c|}
\hline Functional group & Peak $\left(\mathrm{cm}^{-1}\right)$ \\
\hline Primary amines (-NH2 groups) & 3482 \\
\hline C-H stretching vibration (aliphatic) $(\mathrm{CH} 3)$ & $2923.30,2855.38$ \\
\hline C=O stretching vibration (ester) & 1721 \\
\hline C-H bending vibration (aliphatic) $(\mathrm{CH} 2)$ & $1458.08,1367$ \\
\hline C-O stretching vibration (ester) & 1165.07 \\
\hline trans- $\mathrm{CH}=\mathrm{CH}$ & 936,717 \\
\hline
\end{tabular}

\section{NMR analysis}

The presence of flavonoids in aromatic region (quercetin, kaempferol) along with quinones (Thymoquinone, dihydroxythymoquinone) were identified. In addition, the alkaloids and Coumarins were also observed in the spectra which are main features of black seed extract, as shown in Figure 2. 

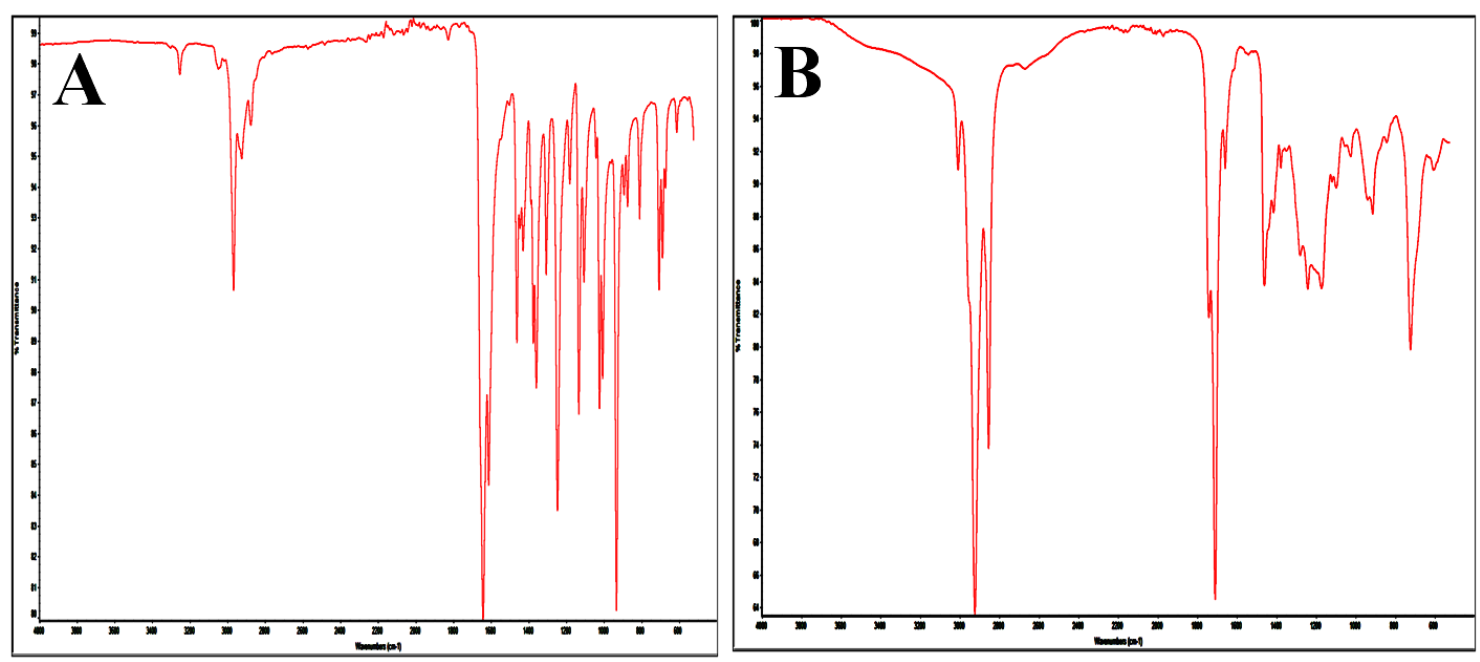

Figure 1. Representative IR spectrum for Thymoquinone A; and Saudi Arabia black seed sample B

\section{Chemical evaluation}

Various chemical tests were performed for the three different black seed samples in order to see the presence of chemical classes. Lipids/fats, phenolic compounds and flavonoids were present in all the three samples, whereas alkaloids, carbohydrates, amino acids, tannins and sterols etc., were not detected in any of the three samples, during chemical tests. Table 4, shows the data for chemical evaluation.

Table 4. Physicochemical evaluation of the three commercial black seed samples

\begin{tabular}{|c|c|c|c|}
\hline \multicolumn{4}{|c|}{ Chemical tests } \\
\hline \multirow{2}{*}{ Chemical class } & \multicolumn{3}{|c|}{ Sample } \\
\hline & Saudi Arabia & Pakistan & India \\
\hline Alkaloids & - & - & - \\
\hline Phenolic compounds & + & + & + \\
\hline Flavonoids & + & + & + \\
\hline Carbohydrates & - & - & - \\
\hline Amino acids & - & - & - \\
\hline Saponins & - & - & - \\
\hline Lipids/Fats & + & + & + \\
\hline Tannins & - & - & - \\
\hline Sterols & - & - & - \\
\hline \multicolumn{4}{|c|}{ Ash values } \\
\hline \multirow{2}{*}{ Ash Values } & \multicolumn{3}{|c|}{ Sample } \\
\hline & Saudi Arabia & Pakistan & India \\
\hline Total ash & $4.16 \pm 0.3 \%$ & $4.35 \pm 0.2 \%$ & $5.16 \pm 0.4 \%$ \\
\hline Acid insoluble ash & $0.27 \pm 0.08$ & $0.48 \pm 0.03 \%$ & $0.63 \pm 0.07 \%$ \\
\hline Water soluble ash & $3.40 \pm 0.4 \%$ & $3.68 \pm 0.2 \%$ & $3.89 \pm 0.3 \%$ \\
\hline
\end{tabular}



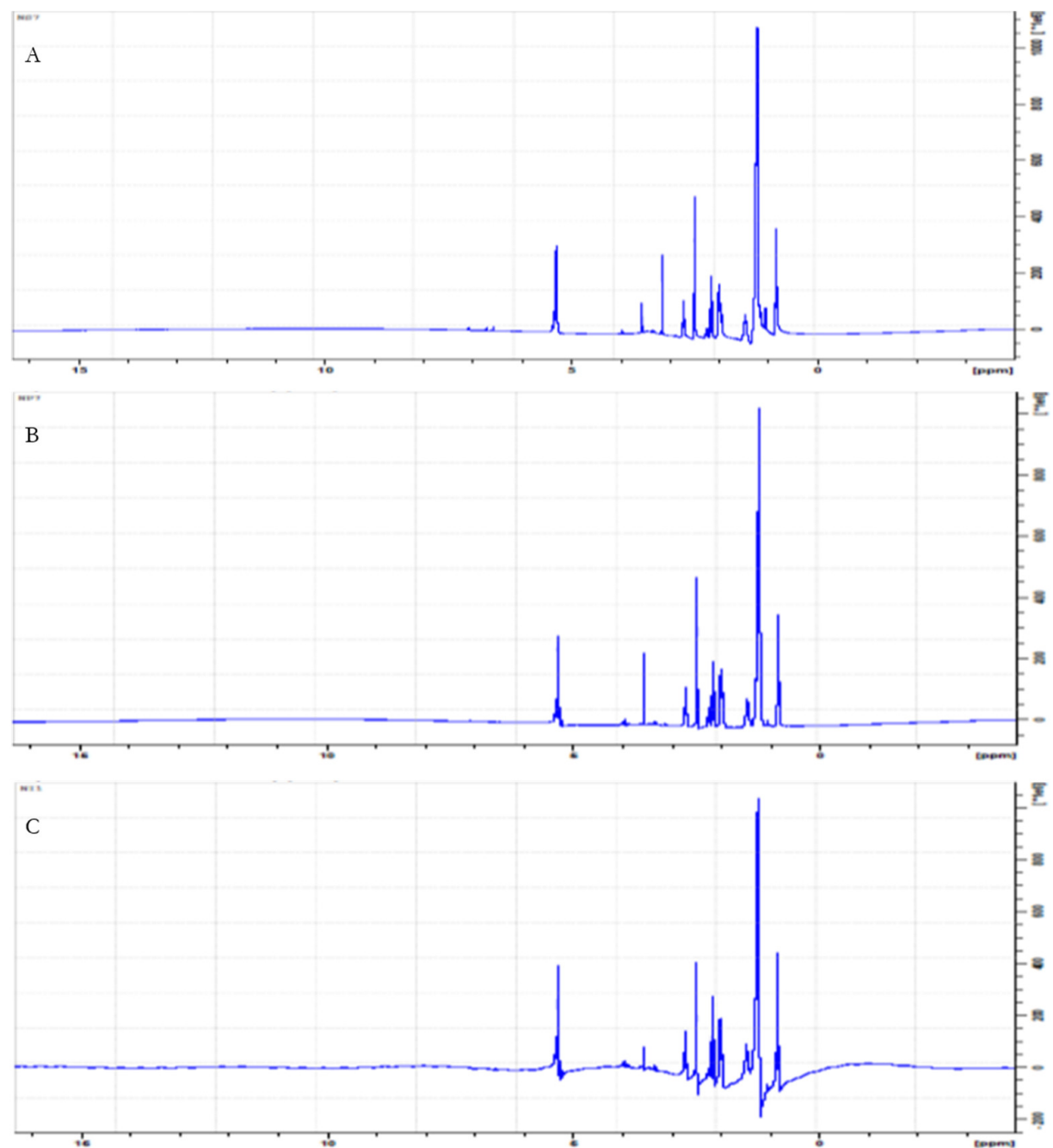

Figure 2. NMR spectra for extracts; Saudi Arabia (A), Pakistan (B) and India (C)

\section{Ash tests value}

The samples were evaluated for ash content including total ash, acid insoluble ash and water-soluble ash. A high total ash was observed for Indian black seed sample ( $5.16 \pm 0.4 \%)$ followed by Pakistani $(4.35 \pm 0.2 \%)$ and Saudi Arabian black seed sample (4.16 $\pm 0.2 \%)$. A similar pattern of high value for acid insoluble and watersoluble ash was observed for Indian sample $(0.63 \pm 0.07 \%$ and $3.89 \pm 0.3 \%)$ followed by Pakistani $(0.48 \pm$ $0.03 \%$ and $3.68 \pm 0.2 \%)$ and Saudi Arabian $(0.27 \pm 0.08$ and $3.40 \pm 0.3 \%)$ black seed sample, respectively. The ash value for all the three samples is shown in Table 4 .

\section{In vitro DPPH activity}

In vitro antioxidant activity showed a low $\mathrm{IC}_{50}$ value of $19.7(\mu \mathrm{g} / \mathrm{mL})$ for Saudi Arabian sample. For Pakistani sample the $\mathrm{IC}_{50}$ value observed was $22.6(\mu \mathrm{g} / \mathrm{mL})$ whereas for Indian sample an $\mathrm{IC}_{50}$ value of 25.3 $(\mu \mathrm{g} / \mathrm{mL})$ was noted (Table 5).

\section{Total antioxidant (ABTS) activity}

A low $\mathrm{IC}_{50}(\mu \mathrm{g} / \mathrm{mL})$ was observed for Saudi Arabian (170), followed by Pakistani and Indian black seed sample with $\mathrm{IC}_{50}$ values of 200 and $240(\mu \mathrm{g} / \mathrm{mL})$, respectively. Table 5, shows ABTS values. 
Table 5. DPPH and ABTS activity $(\mu \mathrm{g} / \mathrm{mL})$ for three black seed commercial samples

\begin{tabular}{|c|c|c|}
\hline Sample & $\begin{array}{c}\text { DPPH } \\
\left(\mathrm{IC}_{50}\right)\end{array}$ & $\begin{array}{c}\text { ABTS } \\
\left(\mathrm{IC}_{50}\right)\end{array}$ \\
\hline Saudi Arabia & 19.62 & 170 \\
\hline Pakistan & 22.54 & 200 \\
\hline India & 25.3 & 240 \\
\hline
\end{tabular}

\section{MTT cytotoxicity study}

The MTT assay for cytotoxicity, showed a potential for the three samples to be cytotoxic in a dose dependent manner. Among the three geographical samples, Saudi Arabian black seed sample revealed more cytotoxicity of $9.4 \%$ live cells over control as compared to live cells of Pakistani (15.6\%) and Indian black seed sample (16.9\%), at 40\% v/v (maximum dose concentration). Overall, Saudi Arabian black seed sample decreases the viable cell count more potently as compared to remaining sample (Figure 3, Table 6).

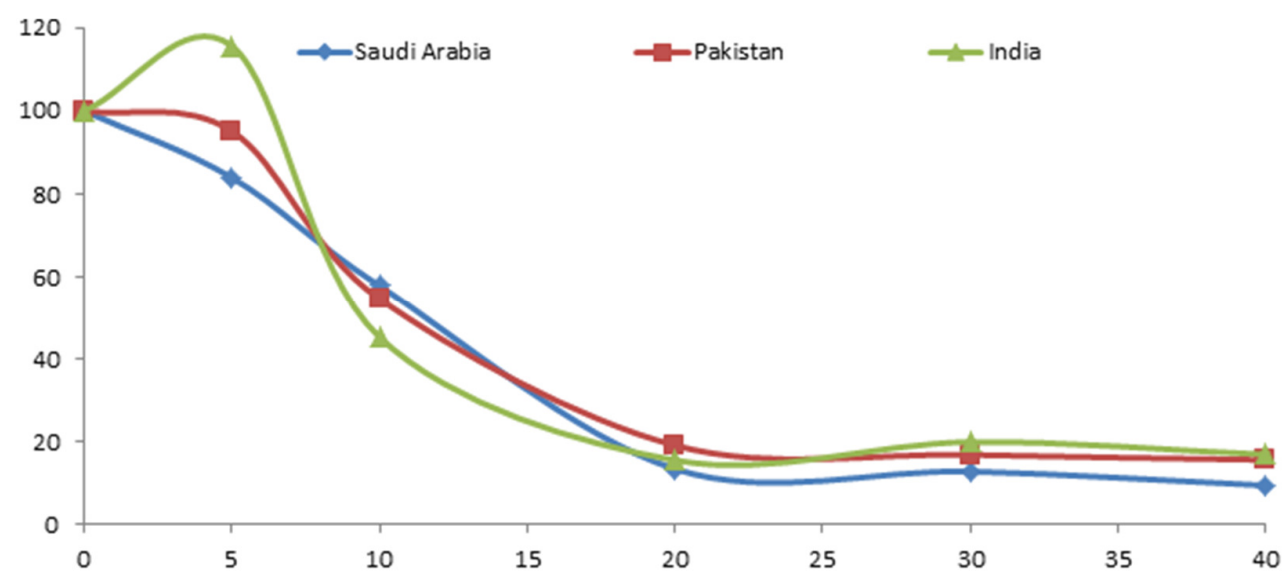

Figure 3. Cytotoxicity pattern for the three commercial samples of black seeds

Table 6. Cytotoxicity profile for the three black seed commercial samples at various concentration

\begin{tabular}{|c|c|c|c|c|c|c|}
\hline \multirow{2}{*}{ Sample } & \multicolumn{7}{|c|}{ Concentration of extract (\%v/v) and cytotoxicity } \\
\cline { 2 - 7 } & $\mathbf{0}$ & 5 & 10 & 20 & 30 & 40 \\
\hline Saudi Arabia & 100 & 83.9 & 57.8 & 13.4 & 12.8 & 9.4 \\
\hline Pakistan & 100 & 95.1 & 54.6 & 19.1 & 16.8 & 15.6 \\
\hline India & 100 & 115.6 & 45.2 & 15.5 & 19.9 & 16.9 \\
\hline
\end{tabular}

Table 7. Principal components loading (PCA) of the data analyzed for three samples

\begin{tabular}{|c|c|c|}
\hline Analysis & PC1 & PC2 \\
\hline Extract value & 0.129 & $\mathbf{0 . 9 9 2}$ \\
\hline DPPH assay & $\mathbf{0 . 9 1 7}$ & 0.399 \\
\hline ABTS assay & $\mathbf{0 . 9 5 2}$ & 0.307 \\
\hline UHPLC-DAD analysis & -0.692 & -0.722 \\
\hline Cytotoxicity assay & $\mathbf{0 . 7 2 8}$ & 0.685 \\
\hline Total ash & $\mathbf{0 . 9 9 9}$ & 0.050 \\
\hline Acid insoluble ash & $\mathbf{0 . 8 8 2}$ & 0.471 \\
\hline Water soluble ash & $\mathbf{0 . 8 8 9}$ & 0.458 \\
\hline Variability \% & 66.739 & 33.261 \\
\hline Cumulative \% & 66.739 & 100.00 \\
\hline
\end{tabular}


Ahmad R et al. (2020). Not Bot Horti Agrobo 48(3):1141-1154

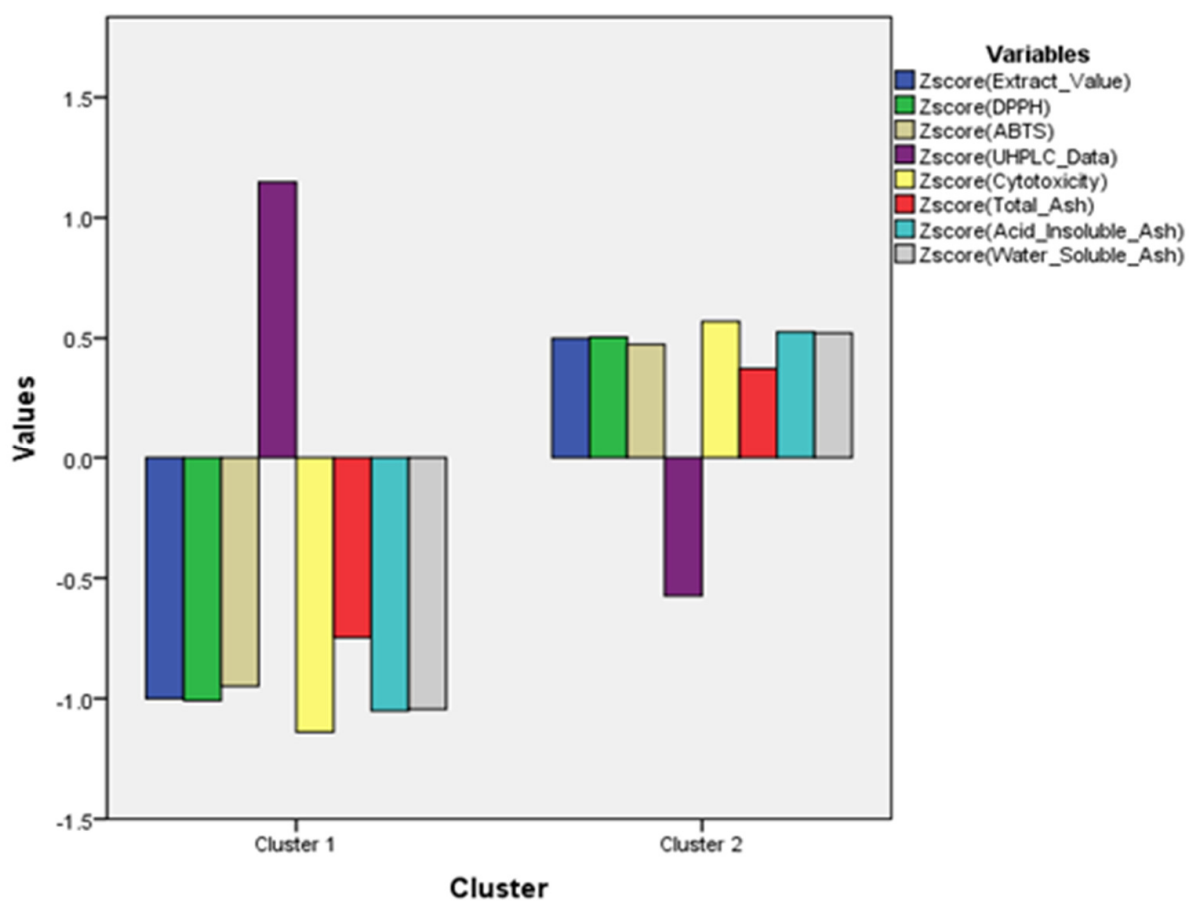

Figure 4. K-mean cluster distribution of analyzed data for the three samples

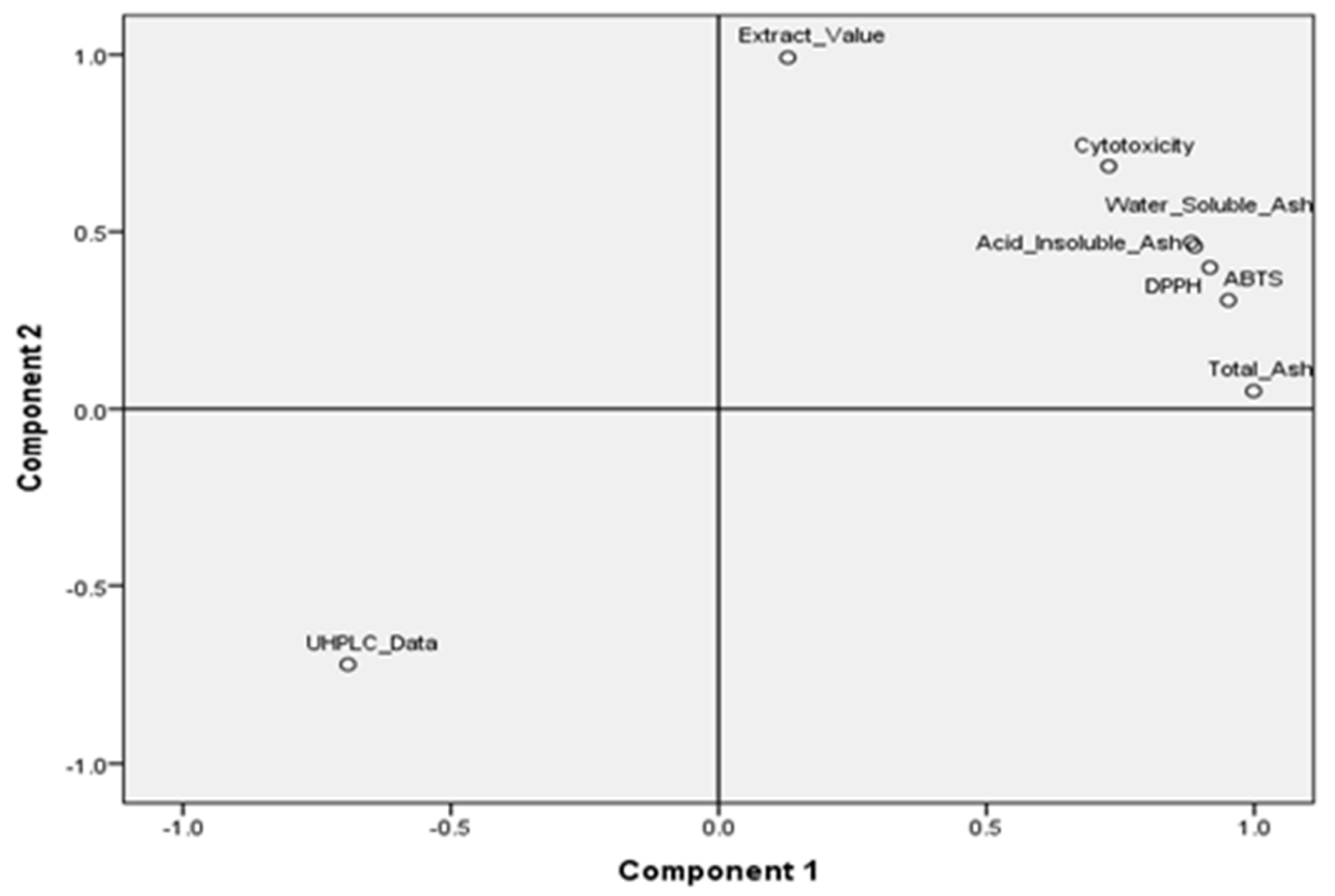

Figure 5. Loading of tested data in principle components 


\section{Discussion}

The study aimed to evaluate the quality of market available food-grade black seed samples. Most of the online available products declares the quality or quantity of active substance in market available products of BS. Hence, the outcomes associated with the use of these low-quality product when applied in various treatments may pose health risks. To evaluate the quality of these products, a need for fast and economical extraction and quantification procedure do exist. Numerous reports regarding THQ extraction and determination are available however, the solvent, temperature, time and sample amount needed as well as the low extract yield make these methods less favorable for standardization. For instance; Soxhlet method with $4 \mathrm{~h}$ (Solati et al., 2013; Kiralan, 2014), hydro-distillation (HD) and steam distillation (SD) with $2 \mathrm{~h}$ as reported by Kokoska et al. (2008), MAE with $1 \mathrm{~h}$ as reported (Kiralan et al., 2014), black seed oil steam distillation (SE-SD) via solvent extraction with 120 h (Kokoska et al., 2008), SC- $\mathrm{CO}_{2}$ with $1 \mathrm{~h}$ (Solati et al., 2013), have been reported. Likewise, the solvent amount used; Soxhlet with $220 \mathrm{~mL}$ (Ahmad et al., 2018), SC-CO $\mathrm{CO}_{2}$ with $150 \mathrm{~mL}$ (Solati et al., 2013) and SE with $200 \mathrm{~mL}$ (Kokoska et al., 2008), have been reported. Herein, ASE was used for THQ extraction. ASE owe the unique feature of using less solvent volume which supports its cost effectiveness. For instance, a solvent volume of $49.5 \pm 2 \mathrm{~mL}$ in a short period of time ( $42 \pm 2 \mathrm{~min}$ ) was taken for ASE in this study, which is the least in any extraction technique reported till date. Herein, the risk of flavonoids degradation is minimal due to shorter extraction exposure. Furthermore, UHPLC technique for THQ quantification was a fast and rapid method with RT of $3.2 \mathrm{~min}$ (runtime $=5 \mathrm{~min}$ ). In the next phase of study, World health organization (WHO) guidelines were applied in order to standardize the samples. (WHO, 2011)

For IR, the analysis revealed presence of specific functional groups with close features to the standarddrug-spectrum of THQ. Our study for THQ-IR corroborate the previous report (Solati et al., 2013). ${ }^{1} \mathrm{H}$ and ${ }^{13} \mathrm{C}$ NMR for high throughput screening and metabolomics analysis of the crude extracts is gaining much wider attention. The samples were subjected to NMR-analysis and the data set obtained for all the sample confirmed the major regions for THQ existence. The data for NMR obtained is completely in agreement with the previously reported extract analysis of black seeds (Javed et al., 2018). Physicochemical evaluation of the samples was performed, in order to standardize the extracts in terms of chemical nature and major chemical classes present. Studies suggests that the presence of chemical classes in a plant are essential for its folklore or therapeutic activity which could be easily linked with the potential a plant exhibits during pharmacological activities (Ahmad et al., 2014). Phytochemical study showed the existence of flavonoids, phenolic compound and lipids/fats whereas the presence of such classes in $\mathrm{n}-\mathrm{Hex}$ has been reported in a number of plant extracts. (Konyalığlu et al., 2005; Sultana et al., 2012; Gurnani et al., 2016;) All the three samples revealed the presence of same chemical classes. The three samples were analyzed for ash values. Due to presence of non-physiological matters in plant materials, ash value presents a narrow range for measurement (Ahmad et al., 2014b). Mostly acid-insoluble ash is given more priority due to the presence of high acid-insoluble materials including silica, sand, and contamination with earthy material. For the samples studied here, a very low amount of acidinsoluble ash was observed. Indian sample was high in acid-insoluble ash value, followed by Pakistani and Saudi Arabian sample. A similar range of ash value have been reported for black seed samples previously (Kumar et al., 2011; Ahmad et al., 2014b) Finally, the extracts were quantified with the help of UHPLC-DAD for the actual concentration of active substance. The amount of $\mathrm{THQ} / \mathrm{mL}$ quantified in the study is more as compared to previous reports (Solati et al., 2013), whereas among the tested samples it was found in the order of Saudi Arabian > Pakistani > Indian extract. These results declare the quality of Saudi Arabian black seed sample comparatively better in terms of ash value, nutritious value and amount of active substance. However, as per WHO guidelines, further biological and pharmacological evaluation was required to validate the final quality. The three samples were evaluated with the help of DPPH, ABTS and MTT study. For antioxidant assays, though free radical was entrapped by all samples, Saudi Arabian black seeds exhibited comparatively high

potential. It may be suggested due to high number of phenolic compounds and flavonoids in n-hex extract of the samples. Similar results are reported earlier (Kumar et al., 2011; Ahmad et al., 2014b). Likewise, the 
cytotoxicity potential for the samples at same doses revealed a more decrease of viable cells for Saudi Arabian sample. For the same reason, black seeds have been evaluated for its anticancer potential in various cell lines, where a significant result has been observed for black seed. (Asaduzzaman and Chun, 2011; Agbaria et al., 2015) The biological activities also favored the Saudi Arabian sample to be significantly better in quality.

\section{Reasons for quality variations}

The sample stored for prolonged period are prone to more risk of phytochemical degradation which may result due to improper storage, storage at unfavorable temperature and humidity as well as shipping. Oxidation/reduction reactions, microbial growth, rancidity of the oil at high temperature and exhaustion are the major reasons. A previous study has evaluated and concluded the effect of oxidative stability at accelerated conditions (Ramadan and Mörsel, 2004). Altitude variation is a considerable factor too. Literature reported more amount of THQ in samples collected from Middle East countries with middle altitudes (Kuwait) (Aziz et al., 2017). Saudi Arabia is situated in a middle altitude region compared to Pakistan and India. Fertilizer nature may affect the quality of a specific phytochemical hence the use of a proper amount and nature of fertilizer have been suggested (Yimam et al., 2015). The effect of geographical location and environment upon the quality of herbal products have been reported previously (Bourgou et al., 2010; Al-Kayssi et al., 2011). In addition, $\mathrm{N}_{2}$ biofertilizer (Azotobacter) increases the productivity and quality of black seed and is a countable factor for quality variation (Tavakkoli et al., 2017). The aforementioned are suggestions based on previous reports and an in-depth exploration is mandatory to understand their effect upon the quality and quantity of THQ in BS.

\section{Yield vs active substance vs activity}

It is evident from the study that more yield may not be a guarantee for more amount of active substance and the more amount of active substance in an extract doesn't always implicate a potent biological or pharmacological activity. As seen earlier in this study, extract yield was more for Pakistani whereas the amount of active substance was more for Saudi Arabian samples. Though significant activities were observed for Saudi Arabian sample, yet, it may not be a surety to declare these activities due to presence of more active substance. It may due to presence of co-chemicals present from other different chemical classes rather than by the major active substance (THQ) as plants are always multi- and complex chemical in nature. Current scenario may be properly explained with a reported example. Piperine in black pepper is considered the major chemical responsible for most of its pharmacological activities however, a study by Sriwiriyajan et al. (2016) using a PFPN (Piperine free Piper nigrum), witnessed a more potent activity for black pepper seeds. This confirms that the active substance responsible for antitumor activity an active substance rather than PPN. It is highly recommendable to properly isolate and study the active substances present in a plant irrespective of focusing the major active/high concentration active substance. Likewise, plants do present the synergistic activity phenomenon (Williamson, 2001), interactions do exist for plants and the problem of more activity for combined extract Vs a single isolated is there. (Rasoanaivo et al., 2011) Different underlying mechanisms are responsible for such synergism and should be explored on individual basis. (Yang et al., 2014)

\section{Conclusions}

Three different geographical origin food-grade samples of black seed (Saudi Arabia, Pakistan, India) were evaluated. Instrumental analysis confirmed the presence of THQ, Ash values assisted in samples standardization whereas, pharmacological and biological models played the role for quality and potency differentiation for all the three samples of black seeds. THQ was observed in all samples however, it was Saudi Arabian sample which revealed a high amount and more potency in terms of activities. An effective 
discrimination of the samples was accomplished using the advanced hyphenated techniques with shorter extraction and quantification methods as well as more reliable and authentic results.

\section{Authors' Contributions}

RA (idea and study design); RA, NA, BMA, ZAA and NAA (literature review and introduction writeup). RA (ASE); RA and NA (UHPLC-DAD and IR); MA (NMR study); BMA, ZAA and NAA (physicochemical tests); FAJ, MHA and HRA (DPPH and ABTS activities); SC and AK (cytotoxicity studies); RA (Data analysis and discussion part). All authors read and approved the final manuscript.

\section{Acknowledgements}

We extend our gratitude to Mr. Intikhab (Lab technician) for his participation in the study.

\section{Conflict of Interests}

The authors declare that there are no conflicts of interest related to this article.

\section{References}

Aboul-Enein HY, Abou-Basha LI (1995). Simple HPLC Method for the Determination of Thymoquinone in Black Seed Oil (Nigella Sativa Linn). Journal of Liquid Chromatography 18(5):895-902. https://doi.org/10.1080/10826079508010400

Agbaria R, Gabarin A, Dahan A, Ben-Shabat S (2015). Anticancer activity of Nigella sativa(black seed) and its relationship with the thermal processing and quinone composition of the seed. Drug Design, Development and Therapy 9:3119-3124. https://doi.org/10.2147/DDDT.S82938

Ahmad F, Husain A, Mujeeb M, Siddiqui NA, Damanhouri ZA (2014b). Physicochemical and phytochemical standardization with HPTLC fingerprinting of Nigella sativa L. seeds. Pakistan Journal of Pharmaceutical Sciences 27(5):1175-1182. PMID: 25176375

Ahmad N, Ahmad R, Al-Layly A, Al-Shawi H, Al-Ali A, Amir M, Mostafa A (2018). Ultra-high-performance liquid chromatography-based identification andquantification of thymoquinone in Nigella sativa extract from different geographical regions. Pharmacognosy Magazine 14(57):471-480. https://doi.org/10.4103/pm.pm_119_18

Ahmad R, Ahmad M, Mehjabeen, Jahan N (2014). Phytochemical screening and Anti-oxidant activity of the two plants Ziziphus oxyphylla Edgew and Cedrela serrata Royle. Pakistan Journal of Pharmaceutical Sciences 27(5):14771482. PMID: 25176241

Ahmad R, Ahmad N, Naqvi A, Exarchou V, Upadhyay A, Tuenter E, ... Pieters L (2016). Antioxidant and antiglycating constituents from leaves of Ziziphus oxyphylla and Cedrela serrata. Antioxidants 5(1):9. https://doi.org/10.3390/antiox5010009

Ahmad R, Ahmad N, Shehzad A (2020). Solvent and temperature effects of Accelerated solvent extraction (ASE) coupled with ultra-high-pressure liquid chromatography (UHPLC-PDA) technique for determination of Thymoquinone in commercial food samples of black seeds (Nigella sativa). Food Chemistry 309(C):125740. https://doi.org/10.1016/j.foodchem.2019.125740

Ahmad R, Ahmad N, Amir M, Aljishi F, Alamer MH, Al-Shaban HR, ... Almofty SA (2020b). Quality variation and standardization of black pepper (Piper nigrum): A comparative geographical evaluation based on instrumental and metabolomics analysis. Biomedical Chromatography 34(3):e4772. https://doi.org/10.1002/bmc.4772 
Al-Kayssi AW, Shihab RM, Mustafa SH, (2011). Impact of soil water stress on Nigellone oil content of black cumin seeds grown in calcareous-gypsifereous soils. Agricultural Water Management 100(1):46-57. https://doi.org/10.1016/j.agwat.2011.08.007

Aziz SA, Kurniawati A, Faridah DN (2017). Changes of thymoquinone, thymol, and malondialdehyde content of black cumin (Nigella sativa L.) in response to Indonesia tropical altitude variation. Hayati Journal of Biosciences 24(3):156-161.https:// doi.org/10.4308/hjb.24.3.156

Bourgou S, Bettaieb I, Saidani M, Marzouk B (2010). Fatty acids, essential oil, and phenolics modifications of black cumin fruit under $\mathrm{NaCl}$ stress conditions. Journal of Agricultural and Food Chemistry 58:12399-12406. https://doi.org/10.1021/jf103415q

Butt UJ, Shah SAA, Ahmed T, Zahid S (2018). Protective effects of Nigella sativa L. seed extract on lead induced neurotoxicity during development and early life in mouse models. Toxicology Research 7(1):32-40. https://doi.org/10.1039/C7TX00201G

Dinagaran, S, Sridhar, S, Eganathan, P (2016). Chemical composition and antioxidant activities of black seed oil (Nigella sativa L.). International Journal of Pharmaceutical Sciences and Research 7(11): 4473. https://doi: 10.13040/IJPSR.0975-8232.7(11).4473-79

Gurnani N, Gupta M, Mehta D, Mehta BK (2016). Chemical composition, total phenolic and flavonoid contents, and in vitro antimicrobial and antioxidant activities of crude extracts from red chilli seeds (Capsicum frutescens L.). Journal of Taibah University for Science 10(4):462-470. https://doi.org/10.1016/j.jtusci.2015.06.011

Iqbal MS, Ahmad A, Pandey B (2018). Solvent based optimization for extraction and stability of thymoquinone from Nigella sativa Linn. and its quantification using RP-HPLC. Physiology and Molecular Biology of Plants 24(6):1209-1219. https://doi.org/10.1007/s12298-018-0593-5

Khan A, Chen HC, Tania M, Zhang DZ (2011). Anticancer activities of Nigella sativa (Black Cumin). African Journal of Traditional, Complementary and Alternative Medicines 8(5):226-232. https://doi.org/10.4314/ajtcam.v8i5S.10

Khandelwal KR (2007). Practical pharmacognosy, techniques and experiments. 17th Edition, Nirali Prakashan Publishers, Pune, India. 9(22):149-154. ISBN13: 9788185790305

Kiralan M, Özkan G, Bayrak A, Ramadan MF (2014). Physicochemical properties and stability of black cumin (Nigella sativa) seed oil as affected by different extraction methods. Industrial Crops and Products 57:52-58. https://doi.org/10.1016/j.indcrop.2014.03.026

Konyalığlu, S, Sağlam, H, \& Kıvçak, B. (2005). $\alpha$-tocopherol, flavonoid, and phenol contents and antioxidant activity of Ficus carica. leaves. Pharmaceutical biology. 43(8): 683-686. doi.org/10.1080/13880200500383538

Linjawi SA, Khalil WK, Hassanane MM, Ahmed ES (2015). Evaluation of the protective effect of Nigella sativa extract and its primary active component thymoquinone against DMBA-induced breast cancer in female rats. Archives of medical science: AMS 11(1):220. https://doi.org/10.5114/aoms.2013.33329

Liu X, Abd El-Aty AM, Cho SK, Yang A, Park JH, Shim JH (2012). Characterization of secondary volatile profiles in Nigella sativa seeds from two different origins using accelerated solvent extraction and gas chromatography-mass spectrometry. Biomedical Chromatography 26(10):1157-1162. https://doi.org/10.1002/bmc.2671

Ramadan MF, Mörsel JT (2004). Oxidative stability of black cumin (Nigella sativa L.), coriander (Coriandrum sativum L.) and niger (Guizotia abyssinica Cass.) crude seed oils upon stripping. European Journal of Lipid Science and Technology 106(1):35-43. https://doi.org/10.1002/ejlt.200300895

Rasoanaivo P, Wright CW, Willcox ML, Gilbert B (2011). Whole plant extracts versus single compounds for the treatment of malaria: synergy and positive interactions. Malaria Journal 10(1):S4. https://doi.org/10.1186/14752875-10-S1-S4

Sharma NK, Ahirwar D, Gupta S, Jhade D (2011). Pharmacognostic standardization, physico and phytochemical evaluation of Amaranthus spinosus linn. Root. Journal of Young Pharmacists 3(3):221-225. https://doi.org/10.4103/0975-1483.83770

Solati Z, Baharin BS, Bagheri H (2014). Antioxidant property, thymoquinone content and chemical characteristics of different extracts from Nigella sativa L. seeds. Journal of the American Oil Chemists' Society 91(2):295-300. https://doi.org/10.1007/s11746-013-2362-5

Srinivasan K (2018). Cumin (Cuminum cyminum) and black cumin (Nigella sativa) seeds: traditional uses, chemical constituents, and nutraceutical effects. Food Quality and Safety 2(1):1-16. https://doi.org/10.1093/fqsafe/fyx031 
Sriwiriyajan S, Tedasen A, Lailerd N, Boonyaphiphat P, Nitiruangjarat A, Deng Y (2016). Anticancer and cancer prevention effects of piperine-free piper nigrum extract on $\mathrm{N}$-nitrosomethylurea-induced mammary tumorigenesis in rats. Cancer Prevention Research 9(1):74-82. https://doi.org/10.1158/1940-6207.CAPR-150127

Sultana M, Verma PK, Raina R, Prawez S, Dar MA (2012). Quantitative analysis of total phenolic, flavonoids and tannin contents in acetone and n-hexane extracts of Ageratum conyzoides. International Journal of Chem Tech Research 3:996-999.

Tavakkoli A, Ahmadi A, Razavi B M, Hosseinzadeh H (2017). Black seed (Nigella Sativa) and its constituent thymoquinone as an antidote or a protective agent against natural or chemical toxicities. Iranian Journal of Pharmaceutical Research 16:2-23.

Trumbo P, Schlicker S, Yates AA, Poos M (2002). Dietary reference intakes for energy, carbohdrate, fiber, fat, fatty acids, cholesterol, protein and amino acids. Journal of the Academy of Nutrition and Dietetics 102(11):1621. https://doi.org/10.1016/s0002-8223(02)90346-9

Williamson EM (2001). Synergy and other interactions in phytomedicines. Phytomedicine 8(5):401-409. https://doi.org/10.1078/0944-7113-00060

Yang Y, Zhang Z, Li S, Ye X, Li, X, He, K (2014). Synergy effects of herb extracts: Pharmacokinetics and pharmacodynamic basis. Fitoterapia 92(1):133-147. https://doi.org/10.1016/j.fitote.2013.10.010

Yimam E, Nebiyu A, Mohammed A, Getachew M (2015). Effect of Nitrogen and phosphorus fertilizers on growth, yield and yield components of black cumin (Nigella sativa L.) at Konta District, South West Ethiopia. Journal of Agronomy 14(3):112-120 https://doi.org/10.3923/ja.2015.112.120
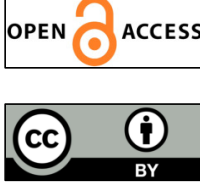

The journal offers free, immediate, and unrestricted access to peer-reviewed research and scholarly work. Users are allowed to read, download, copy, distribute, print, search, or link to the full texts of the articles, or use them for any other lawful purpose, without asking prior permission from the publisher or the author.

License - Articles published in Notulae Botanicae Horti Agrobotanici Cluj-Napoca are Open-Access, distributed under the terms and conditions of the Creative Commons Attribution (CC BY 4.0) License. (c) Articles by the authors; UASVM, Cluj-Napoca, Romania. The journal allows the author(s) to hold the copyright/to retain publishing rights without restriction. 